\title{
Providing Cavitation-Free Operation of Hydraulic Systems under Passing Load in Hydraulic Actuator
}

\author{
Liliya Salimovna Musina ${ }^{1}$, Dmitry Vladimirovich Tselischev ${ }^{1}$, Vladimir Aleksandrovich Tselischev ${ }^{1}$, Sergey \\ Yurievich Konstantinov $^{1} \&$ Ramil Salimovich Musalimov ${ }^{1}$ \\ ${ }^{1}$ Ufa State Aviation Technical University, Russia \\ Correspondence: Liliya Salimovna Musina, Ufa State Aviation Technical University, Russia. E-mail: \\ yurioki@ya.ru
}

Received: October 30, 2014

Accepted: November 6, $2014 \quad$ Online Published: March 15, 2015

doi:10.5539/mas.v9n4p276

URL: http://dx.doi.org/10.5539/mas.v9n4p276

\begin{abstract}
The problems of braking and positioning of hydraulic actuators are an integral part of output speed control in hydro-pneumatic actuators. This article is focused on a hydraulic braking of driven elements of machines and mechanisms which is carried out by devices known as brake valves (counterbalance, load control, over-centre valves). Brake valves are used to exclude overrunning speed under passing loads when the external load direction coincides with the direction of movement (rotation) of the hydraulic actuator. They provide a constant pressure in pressure line and prevent cavitation. In this article the design and operation of brake valves are analyzed. The need for brake valves in hydraulic machines with hydraulic actuators under a passing load is proved. As a result of theoretical research a mathematical model of dynamics of hydraulic actuator with a brake valve has been developed. This model unlike others takes into account the design of main and control spools of the brake valve. The problem of logging-running unit braking is solved by the use of the hydraulic brake valve as a part of hydraulic logging system.
\end{abstract}

Keywords: brake valve, counterbalance valve, load control valve, cavitation, hydraulic system, logging system

\section{Introduction}

\subsection{Introduction to the Problem of Braking}

At present the problems of experimental theoretical simulation of automatic braking systems used in hydraulic and pneumatic units are investigated insufficiently, but computer simulation and modern application package can solve the problems of analysis and synthesis of hydraulic and pneumatic brake devices. These problems force to search new structures by developing generalized variants of the problems solutions, analyzing these options, research forecasting, finding compromise solutions under multicriteriality and uncertainty.

The analysis of technical literature on hydraulic braking systems shows that the problem of hydraulic actuator braking under passing load is rather complicated and requires a careful performance calculation and selection of brake devices design (Raines, 1980; Levitsky and Tsuhanova, 1988). Brake devices are effective if they reduce dynamic load and vibrations of executive units and links of mechanisms.

The problems of braking and positioning of hydraulic actuators are an integral part of the problems of speed control of output link of hydraulic and pneumatic actuators.

There are different types of brake devices applied mainly for braking of working units and links of machines with hydraulic and pneumatic actuators (He et al., 2012; Filipov et al., 1983).

\subsection{Design Problems of Braking Devices}

In designing brake devices the law of momentum is revealed by the analysis of machine operation and specifications. Then a way of braking action is chosen from a wide range of variants. Here functionality, characteristics and features of brake device should be taken into account as well as possible loads and movement requirements of the hydraulic actuator during braking action.It is necessary to define the characteristic of a hydraulic actuator subjected to change by the control device to execute the set law of momentum. Analysis of the obtained characteristic and the motion equation of hydraulic actuator shows if a simple brake device can be applied. In case of significant design and technological difficulties, we can divide them into primary and 
secondary ones by analysis of movement requirements, i.e. define, what derogations from the optimum law of momentum are admissible without machine deterioration. To find out if simple brakes are near optimal, it is necessary to examine capacity of each brake device. A law of motion in the form of the function, which can describe braking process in respect of "the way" or "the time".

Engineering design of hydraulic actuator brakes includes the following tasks: choosing the braking law or formulating the main restrictions of the braking law, specified by a certain task; determining the braking force to provide the braking law or quality of braking process; determining (synthesizing) design requirements and control of the brake device, i.e. the law of change of control in the function of way or time, required for the desired force of braking; dynamic analysis of braking process with account of all components of braking forces; thermal calculation; strength calculations of elements.

It is necessary to state an approximate synthesis techniques of brake devices under the desired braking law, which is applicable to ways of braking of the second group (Tsuhanova and Yashina, 1984), since these ways are the most universal and common compared with other ways of braking. The same procedure can be applied for brake devices of other groups of the control hydraulic units, which are used to accelerate the hydraulic actuator under the desired law.

In case of the second way of braking a hydraulic characteristic of hydraulic lines is variable and as a rule the moving element of brake device changes the channel cross-section (Sveshnikov, 1995). Therefore the dimensions calculation of the working elements of braking system contains the following stages: defining the flow effective cross-section in the brake device necessary for the desired law; finding effective cross-section with different spool positions; dimensions calculation of the working elements and spool drive for approximation to the desired law; compliance test of the necessary and realized areas; finding of the law of movement, which will be obtained when using the calculated dimensions of working elements; the analysis of the received law and a comparison with the laws obtained by other forms of working elements; choice of the law of momentum and a form of the working elements most suitable for each case.

Studying the properties of each form, simple in production, for the whole range of typical hydraulic systems is a difficult task.

This article concentrates on a hydraulic way of braking of working machines and mechanisms which is carried out by the devices known as the brake valves.

Basically, brake valves are intended to maintain the set speed, the working units movement due to external passing load and to provide the equipment workholding in hydraulic systems of construction, road and municipal machines.

\section{Materials and Methods}

\subsection{Brake Valves Characteristics}

Brake valves are used to exclude overrunning speed at passing load when the movement direction of the external load coincides with the direction of movement (rotation) of the hydraulic actuator, and they maintain constant pressure in pressure line. The pressure should exceed saturated vapor pressure of the liquid to avoid cavitation.

Cavitation occurs in pressure line of hydraulic actuator due to passing load, the hydraulic motor starts to work as a pump and pressure line becomes a suction line with pressure falling in it. Pressure drop to a level of saturated vapor pressure of liquid results in cavitation accompanied by rapid release of gas from the liquid and foam in pressure line, unstable work of a hydraulic system which can lead to uncontrollable rotation of a hydraulic motor and freight fall. Decontamination, degassing, purification of actuation fluid of a hydraulic actuator as a rule have a negative effect - cavitation occurs anyway. In order to avoid this phenomenon the hydraulic system needs to be equipped with the brake valves ensuring its cavitation-free functioning (Gallyamov et al., 2008).

Thus, brake valves are used to provide constant speed of load drop and if necessary to control the speed reduction by regulation of pressure in the outlet line of the hydraulic motor irrespective of the load made by fright (prevention of overrunning).

Brake valves are manufactured by many companies, such as Rexroth, Hydac, Parker, Oleostar, Fluid Press, etc.

\subsection{Operation Principles and Investigated Scheme of Brake Valves}

Usually the brake valve is installed in the pressure line of hydraulic actuator and controls pressure in it (control port X on Figure 1). Depending on the level of control pressure the brake valve opens or closes at the amount inversely proportional to the external passing load. As a result the speed drop of load (arm of crane) remains constant. The spool placed in the valve body in the "closed" position is held by a spring. Stable operation that 
excludes spool fluctuation is provided by two adjustable throttles with check valves which throttle independently the inlet and outlet flows of the actuation fluid.

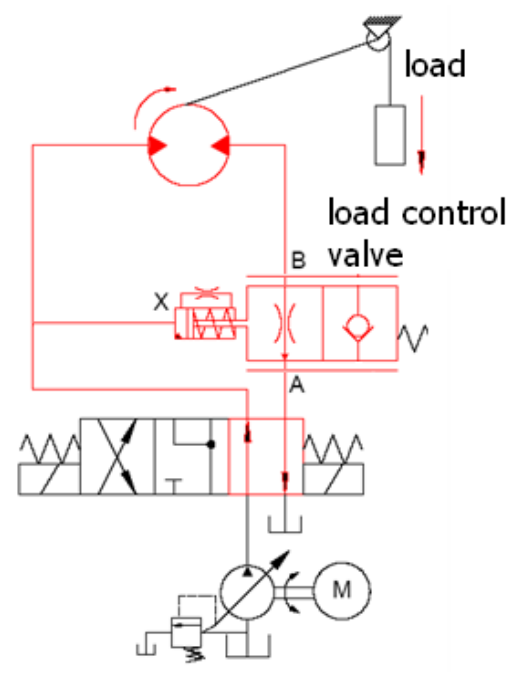

Figure 1. Scheme of the brake valve in a hydraulic system at load drop

Let's consider the operation of brake valve presented in Figure 2. The main parts of the brake valve are: valve body (1), the main spool (2), pilot stage (3), the control spool (4), the damping spool (5) and throttle (6).

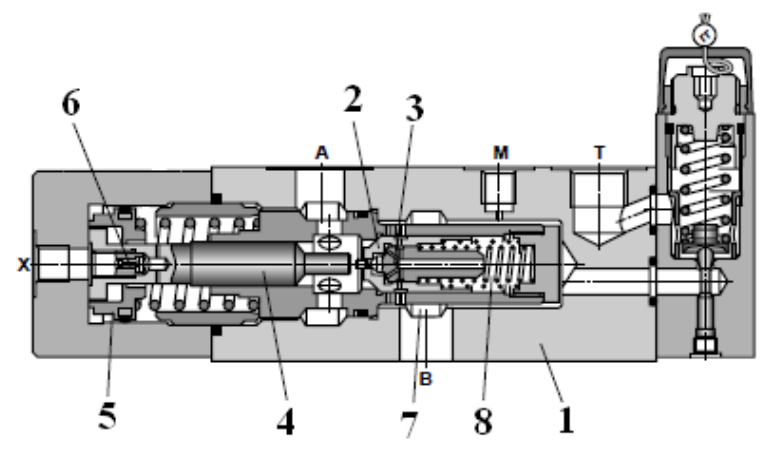

Figure 2. The brake valve construction. Rexroth RRS27551/09.97

\subsection{Lifting the Load}

With free-flow from A to B the main spool (2) is opened. If the load pressure falls (e.g. pipe break between the directional valve and port A) then the main spool (2) immediately closes. This function is performed by the connection of the load side (7) with chamber (8).

\subsection{Lowering the Load (Circuit Examples)}

The direction of flow is from B to A. Port A is connected to the tank via the directional valve. The cylinder end is connected to a flow line which corresponds to the operation conditions. The relationship between the control pressure at port $\mathrm{X}$ and the load pressure at port $\mathrm{B}=1: 20$.

When the control pressure is reached the pre-opening of the main spool takes place. The control spool (4) shifts opening the pilot stage (3) and the chamber (8) is connected with the tank via port A and is de-compressed. At the same time the load pressure in port B is no longer applied to chamber (8) due to the longitudinal movement of the pilot stage (3) within the main spool. The main spool (2) is thereby unloaded. The end of the control spool (4) thrusts against the main spool (2) and the collar thrusts against the damping spool (5).

The pressure required at port $\mathrm{X}$ to connect $\mathrm{B}$ and $\mathrm{A}$ only depends on the chamber (9) spring force. The pressure required to start opening the connection $\mathrm{B}$ to $\mathrm{A}$ is $20 \mathrm{bar}$; the full opening requires 50 bar. 
The opening cross-section for flow control increases progressively while the radial drillings in the bush closed by the main spool (2) are opening.

The relationship between the control pressure, cracking pressure and differential pressure determines the flow to the actuator via the connection of B to A. Thus uncontrolled running away of the actuator is prevented.

The controlled lowering procedure is not affected even in the case of a pipe break between the directional valve and port A (Product Catalog. Mannesmann Rexroth RE 27 551/06.03).

\subsection{Selection of the Brake Valve}

The design of brake valves of various manufacturers does not differ much. The calculation and selection of the valve is carried out depending on such key parameters as flow rate, control pressure at port X, load pressure at port B, and also the ratio of these pressures (see Figure 1) defining a pilot ratio of the control plunger of brake valve (Sunarchin, 2005).

\subsection{Mathematical Model of Braking Process}

For research of the braking process at the passing load it is possible to use the following mathematical model:

The momentum equation:

$$
J \cdot \frac{d \omega}{d t}=M \cdot g \cdot R-\frac{p_{p} \cdot V_{\mathrm{w}}}{2 \pi \cdot \eta_{\mathrm{m}}}-k_{w} \cdot \omega,
$$

Where $J$-integral inertia:

$$
J=J_{1}+J_{2}+M \cdot R^{2}, J=J_{1}+J_{2}+M \cdot R^{2},
$$

$J_{1}$ - hydraulic motor inertia; $J_{2}$ - drum inertia; $W$ - angular frequency of motor revolution; $M$ - load weight; $g$ - acceleration of gravity; $R$-drum radius; $P_{p}$ - pump rating pressure; $V_{w}$ - motor displacement; $\eta_{m}-$ mechanical efficiency; $K_{w}$ - viscous drag coefficient.

The mass flow balance equation:

$$
Q_{p}=V_{w} \cdot n \cdot \eta_{m}=\mu \cdot f(p) \cdot \sqrt{\frac{2}{\rho} \cdot\left(p_{p}-p_{t}\right)}+\frac{V_{o}}{E} \cdot p_{p}
$$

where $\mu$ - flow coefficient; $f(p)$ - throttle area depending on pump pressure, $\rho$ - fluid density; $P_{t}-\operatorname{tank}$ pressure; $V_{0}$-throttle displacement; $E$ - modulus of bulk elasticity.

The motion equation of the control spool:

$$
m_{c s} \cdot \frac{d v_{c s}}{d t}=\left(p_{c}-p_{t}\right) \cdot F_{\mathrm{cs}}-k_{v} \cdot \frac{d x_{c s}}{d t}-F_{f} \cdot \operatorname{sign}\left(\frac{d x_{c s}}{d t}\right),
$$

Where $m_{c s}$-control spool weight; $V_{c s}-$ control spool movement speed; $p_{c}$-control pressure in which the main spool starts to open; $F_{c s}-$ control spool area; $K_{v}$ - viscous drag coefficient; $X_{c s}$ - control spool movement; $F_{f}$ - dry friction force.

The motion equation of the main spool:

$$
m_{m s} \cdot \frac{d v_{m s}}{d t}=\left(p_{c}\left(x_{m s}\right)-p_{t}\right) \cdot F_{m s}-k_{v} \cdot \frac{d x_{m s}}{d t}-C_{m s} \cdot x\left(x_{m s}\right)-F_{f} \cdot \operatorname{sign}\left(\frac{d x_{m s}}{d t}\right),
$$

Where $m_{m s}-$ main spool weight; $v_{m s}$ - main spool movement speed; $p_{c}\left(x_{m s}\right)$-control pressure; $F_{m s}$ - main spool area; $C_{m s}-$ deflection rate of elastic support of main spool; $x\left(x_{m s}\right)$ - movement value depending on 
position of the control spool.

The mass flow balance equation through the i-slot of the main valve spool:

$$
m_{m s} \cdot \frac{d v_{m s}}{d t}=\left(p_{c}\left(x_{m s}\right)-p_{t}\right) \cdot F_{m s}-k_{v} \cdot \frac{d x_{m s}}{d t}-C_{m s} \cdot x\left(x_{m s}\right)-F_{f} \cdot \operatorname{sign}\left(\frac{d x_{m s}}{d t}\right)
$$

\section{Results}

\subsection{Results of Numerical Research}

Mathematical model for dynamics of hydraulic actuator with the brake valve at the passing load includes the equations (1) - (5). The numerical solution of system of equations by the Runge-Kutta method is presented in Figures 3 and 4.

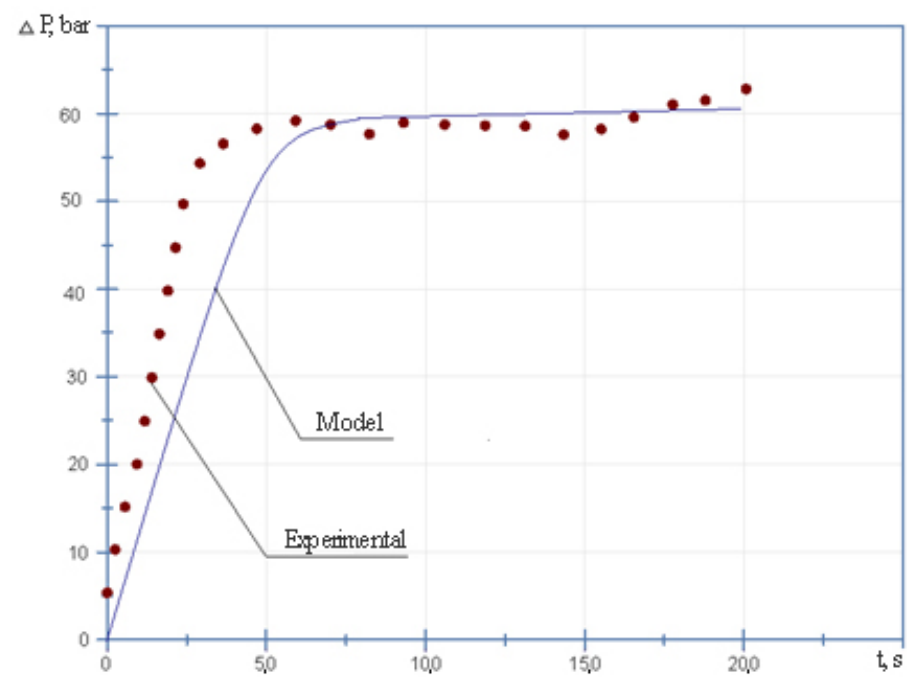

Figure 3. Pressure drop on the brake valve

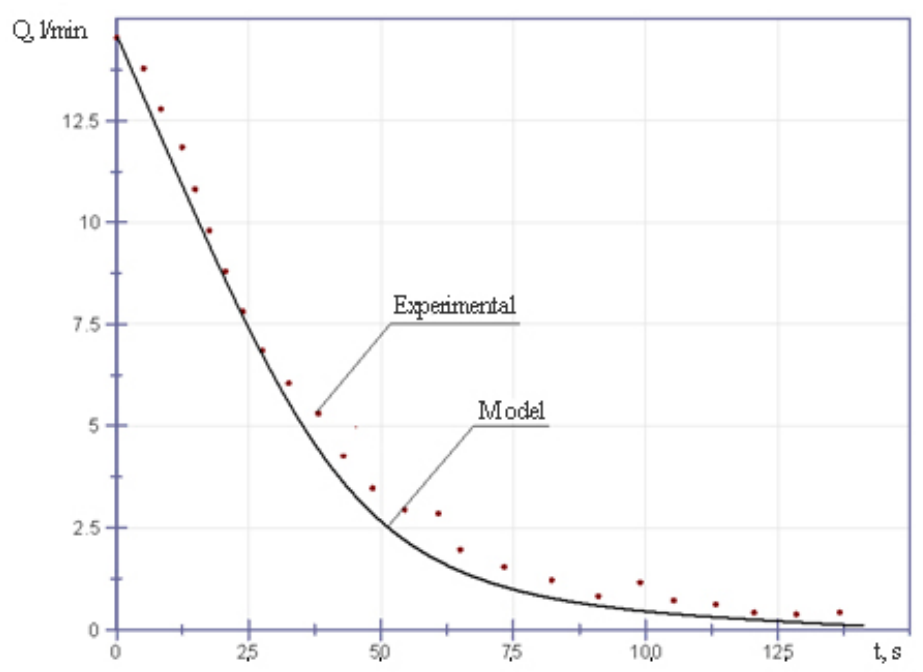

Figure 4. Mass flow through the brake valve 


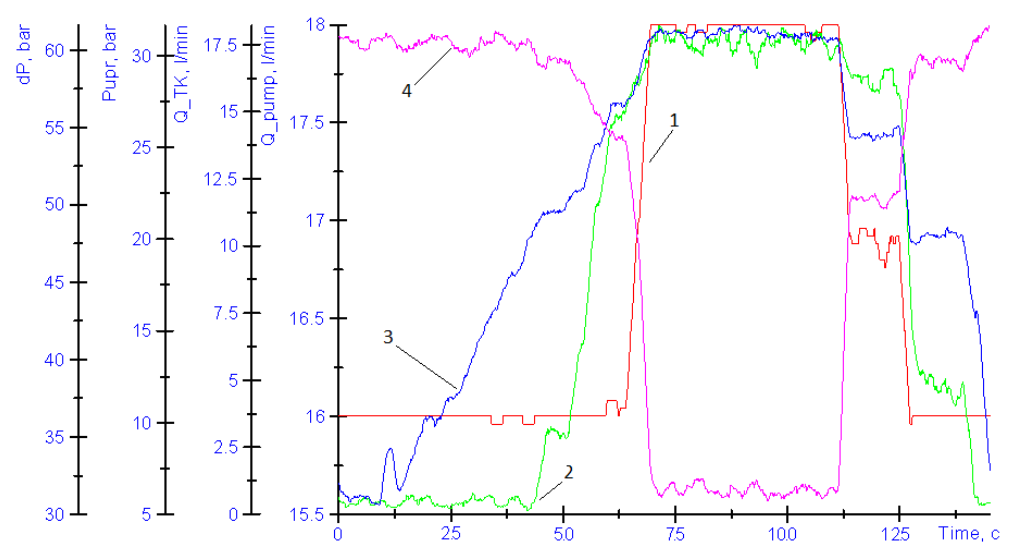

Figure 5. Brake valve dynamic characteristics (Parker E2A060ZN)

The developed mathematical model adequately describes the dynamics of hydraulic actuator with the brake valve. The error of modeling doesn't exceed 9\% (Gimranov et al., 2014).

\subsection{Results of Experimental Research}

Experimental researches of brake valves were carried out on the base of Educational Scientific Innovative Center "Gidropnevmoavtomatika" in Ufa State Aviation Technical University at the "Diagnostics and Identification of Hydraulic Systems" stand of production of company "Hydac" (Poland).

The action of passing load resulting in pressure drop in the delivery line of the hydraulic motor was simulated at the bench. As the pressure line of the hydraulic motor is connected to the control line of the brake valve (see Figure 1), the proportional throttle of indirect action built in the valve, limiting the mass flow of liquid in the tank line of the hydraulic motor, prevented further pressure drop in the pressure line. Thus, the brake valve provided a cavitation-free operation of a hydraulic system with a rotary hydraulic actuator at the passing load.

In Figure 5 initial results of dynamic experimental research of brake valves at the experimental bench are shown. Two brake valves made by Parker E2A060ZN and HYDAC SVBE-R1-01 were studied.

\subsection{Application of Research Results}

As a result of cooperation of Ufa State Aviation Technical University and "Tuymazinsky Plant of the Geophysical Equipment" (JSC "TZGOIA") company a prototype of the Logging-Running Unit with the hydraulic drive as a part of the Self-Propelled Logging System PKS-5G series was developed in 2008.

The Logging System PKS-5G is designed for geophysical exploration in exploratory and drilling wells and for development and control in operating wells. The logging cable diameter is 12,3 $\mathrm{mm}$. Exploration depth doesn't exceed $5000 \mathrm{~m}$.

Hydraulic SPA drive is carried out by the power take-off which in turn is driven by the engine of KamAZ. Hydraulic motor is driven by the pump unit produced by the "PSM Hydraulics". The pump station consists of two main adjustable bent axis-piston pumps and an auxiliary axial-piston pump. During operation both main pumps are used simultaneously. Pump pressure lines are combined and mass flow entering the common pressure line is summarized from two pumps. Pressure is equal for each pump and corresponds to the load at the output the hydraulic motor. Drive moments on each of pumps are shared equally.

Control functions of Logging-Running Unit are concentrated in one multifunctional control lever of pump (joystick). Depending on the lever tilt the mass flow of main pumps changes resulting in process acceleration during lifting and lowering. The lever while released comes back to rest position and pumps come to zero delivery, thus braking the drum completely. A 30 degree deflection from rest position corresponds to change of displacement of the main pumps from minimum to the maximum value.

When lifting a 4 ton-cable from the maximum depth of $5000 \mathrm{~m}$ the pressure developed by pump group was $18 \mathrm{MPa}$. Speed of cable lifting and lowering ranged from 11 to $8000 \mathrm{~m} /$ hour. The rated flow of delivery fluid of $200 \mathrm{l} / \mathrm{min}$ corresponded to the frequency of drum rotation of $40 \mathrm{rpm}$.

During cable payout there appeared a passing load having a tendency to accelerate payout. To prevent 
uncontrollable payout and to provide cavitation-free operation of a lowering contour in the hydraulic system the block of brake valves was installed (Bosch-Rexroth FD 25 PA - 2X / B04V). The block fixed the drum at zero pressure in the pressure line, allowed to carry out controlled braking action and to regulate the speed of lowering a cable in the range from 11 to $8000 \mathrm{~m} /$ hour, and also to provide a cavitation-free mode of lowering a 4 ton-cable.

\section{Discussion}

Basic research of brake systems allowed to receive quantitative characteristics of brake system operation and to describe their work in a dimensionless form (Xu, B., et al., 2013; Straky, 2003).

Works on hydraulic proportional valves allowed to find the best approach to the study of devices affected by cavitation (Amirante, R., et al., 2014).

Unfortunately the problem of studying and designing brake devices is being solved now only by their direct producers, though basic research isn't conducted (Production catalog. Mannesmann Rexroth, 2014). This subject was reflected in a number of modern inventions and research works (Rybak, 2008; Zhang, et al., 2010; Liu, et al., 2011).

The problem of providing cavitation-free operation of hydraulic systems is well studied. However the special case of cavitation in the hydraulic engine at passing load requires intensive research (Zhang, et al., 2012).

\section{Conclusion}

The article analyzes the principles of brake valves operation and design. The necessity of applying brake valves in hydraulic engines affected by passing load is confirmed.

The theoretical research resulted in the dynamic mathematical model of the hydraulic drive with the brake valve. The error for the mathematical model describing dynamics of the hydraulic drive with a brake valve in comparison with experiment doesn't exceed $9 \%$.

The solution of a problem of braking action of a Logging-Running Unit by using the hydraulic brake valve as a part of hydraulic Logging System PKS-5G is shown.

Tests showed stable operation in all modes of the cable lifting and lowering with constant speed in the range from 11 to $8000 \mathrm{~m} /$ hour and at zero cavitation in hydraulic system.

Further research of fluid influence (such as viscosity and surface tension force) on braking process is supposed to be continued.

\section{Acknowledgments}

We are responsible for all errors as well as heavy style of the manuscript.

\section{References}

Amirante, R., Distaso, E., \& Tamburrano, P. (2014). Experimental and numerical analysis of cavitation in hydraulic proportional directional valves. Energy Conversion and Management, 11(87), $208-219$. http://dx.doi.org/10.1016/j.enconman.2014.07.031

Filipov, I., Raitsin, M., \& Grigoriev, N. (1983). Positioning working bodies systems of industrial air robots. Overview, M. NIImash, 24, 48-72.

Gallyamov, S., Shirokova, K., Tselishchev, V., \& Tselishchev, D. (2008). The research of aircraft hydraulic $\begin{array}{lllll}\text { control } \quad \text { drive. } & \text { Vestnik } & \text { 66-73. }\end{array}$ http://old.ugatu.ac.ru/publish/vu/stat/UGATU-2008-2\%2829\%29/10.pdf

Gimranov, E., Musina, L., \& Tselishev, V. (2014). Braking system research under backload. Vestnik UGATU, 7(18 (1(62))). Retrieved August 31, 2014, http://journal.ugatu.ac.ru/index.php/vestnik/article/view/811/767

He, L., Wu, J. L., Peng, M. L., Hou, Y. M., \& Chen, L. P. (2012). Modeling and Co-Simulation for Air Brake System of Heavy Truck. Advanced Materials Research, 466-467, 1109-1114. http://dx.doi.org/10.4028/www.scientific.net/amr.466-467.1109

Levitsky, N., \& Tsuhanova, E. (1988). Pneumatics and Hydraulics. M: Engineering. Calculation braking hydraulic control devices for time, 30, 256.

Liu, Z., Jing, H., \& Chen, H. (2011). Flow-valve modelling and wheel-slip control for an automotive hydraulic anti-lock braking system. Proceedings of the Institution of Mechanical Engineers, Part D: Journal of Automobile Engineering, 225(12), 1565-1577. http://dx.doi.org/10.1177/0954407011411390 
Product Catalog. Mannesmann Rexroth RE 27 551/06.03. (n.d.). Bosch Rexroth. Retrieved August 31, 2014, http://www.boschrexroth.com/RDSearch/rd/r_27551/re27551_2003-06.pdf

Raines, J. (1980). Manage pneumatic braking backpressure. The dynamics and strength questions, Riga, 11(7), $88-95$.

Rybak, A. (2008). Modelling and optimization of mobile machines and technological equipment hydro systems. PhD thesis, Kuban State Technological University, Krasnodar, 25, 25.

Straky, H., Kochem, M., Schmitt, J., \& Isermann, R. (2003). Influences of braking system faults on vehicle dynamics. Control Engineering Practice, 11(3), 337-343. http://dx.doi.org/10.1016/s0967-0661(02)00301-5

Sunarchin, R. (2005). Study Guide, USATU. Ufa: Selection of parameters hydromechanical controls of aircraft engines. Numerical methods for the study.

Sveshnikov, V. (1995). Directory: Machinostroenie. Pњoscow: Machine hydraulic actuators.

Tsuhanova, E., \& Yashina, M. (1984). Calculation of parameters of hydraulic dampers with discretely changing windows. Pneumatics and Hydraulics, Mashinostroenie, 300, 256-261.

Xu, B., Cheng, M., Yang, H., Zhang, J., \& Yang, M. (2013). Safety brake performance evaluation and optimization of hydraulic lifting systems in case of overspeed dropping. Mechatronics, 23(8), 1180-1190. http://dx.doi.org/10.1016/j.mechatronics.2013.10.005

Zhang, H., \& Zhang, L. (2012). Numerical simulation of cavitating turbulent flow in a high head Francis turbine at part load operation with OpenFOAM. Procedia Engineering, 31, 156-165. http://dx.doi.org/10.1016/j.proeng.2012.01.1006

Zhang, J., Chen, X., \& Zhang, P. (2010). Integrated control of braking energy regeneration and pneumatic anti-lock braking. Proceedings of the Institution of Mechanical Engineers, Part D: Journal of Automobile Engineering, 224(5), 587-610. http://dx.doi.org/10.1243/09544070jauto1307

\section{Copyrights}

Copyright for this article is retained by the author(s), with first publication rights granted to the journal.

This is an open-access article distributed under the terms and conditions of the Creative Commons Attribution license (http://creativecommons.org/licenses/by/3.0/). 